\title{
INVESTIGASI ONLINE RESILIENCE REMAJA: EKSPLANASI PERANAN KARAKTERISTIK REMAJA, KARAKTERISTIK KELUARGA, KELEKATAN REMAJA-ORANG TUA, REGULASI EMOSI, DAN HUBUNGAN PERSAHABATAN
}

\author{
Raihan 'Ainun Hasanah ${ }^{1^{*}}$, Melly Latifah' \\ ${ }^{1}$ Departemen IImu Keluarga dan Konsumen, Fakultas Ekologi Manusia, \\ IPB University, Bogor 16880, Indonesia
}

")E-mail: raihan_ainun@apps.ipb.ac.id

\begin{abstract}
Abstrak
Penggunaan media sosial telah membawa sejumlah masalah bagi remaja seperti perundungan siber maupun pengalaman tidak nyaman lainnya sehingga remaja membutuhkan sebuah kemampuan untuk menghadapinya, yaitu online resilience. Penelitian ini bertujuan untuk menganalisis pengaruh karakteristik remaja, karakteristik keluarga, kelekatan remaja-orang tua, regulasi emosi, dan hubungan persahabatan terhadap online resilience pada remaja. Penelitian ini menggunakan pendekatan kuantitatif dan desain eksplanatori dengan melibatkan 224 remaja pengguna media sosial usia 15-18 tahun yang tinggal bersama orang tua lengkap dan tinggal di Kota Bogor. Teknik penarikan contoh yang digunakan adalah purposive sampling. Data diperoleh dengan pelaporan diri melalui kuesioner daring dan dianalisis dengan uji regresi linear berganda. Hasil menunjukkan bahwa lebih dari separuh remaja memiliki kelekatan dengan ayah kategori rendah $(53,1 \%)$ dan kelekatan dengan ibu kategori sedang $(51,3 \%)$. Sementara itu, lebih dari separuh remaja $(61,2 \%)$ memiliki regulasi emosi penilaian ulang kategori sedang dan lebih dari sepertiga remaja (38,8\%) memiliki regulasi emosi penekanan emosi kategori rendah. Selanjutnya, lebih dari separuh remaja memiliki hubungan teman sebaya kategori tinggi $(68,3 \%)$ dan online resilience kategori sedang $(57,1 \%)$. Hasil uji regresi $\left(R^{2}=0,394\right)$ menunjukkan bahwa jenis kelamin remaja, pendapatan per kapita, regulasi emosi penilaian ulang, dan hubungan persahabatan berpengaruh terhadap online resilience remaja. Implikasi hasil penelitian terhadap cara peningkatan online resilience dibahas lebih lanjut dalam artikel ini.
\end{abstract}

Kata kunci: hubungan persahabatan, kelekatan remaja-orang tua, online resilience, regulasi emosi, remaja

\section{Investigating Adolescent's Online Resilience: An Explanation of Adolescent Characteristics, Family Characteristics, Adolescent Attachment to Parents, Emotion Regulation, and Peer Relationship}

\begin{abstract}
The use of social media has brought a number of problems for adolescents such as cyber bullying and other uncomfortable experiences so that adolescents need an ability to deal with it, namely online resilience. This study aims to analyze the influence of adolescent characteristics, family characteristics, adolescent attachment to parents, emotion regulation, and peer relationship toward adolescents' online resilience. This study used a quantitative approach and an explanatory design involving 224 adolescent social media users aged 15-18 years who live with their parents and live in Bogor City. The sampling technique was purposive sampling. Data were obtained by self-reporting through online questionnaires and analyzed using multiple linear regression tests. The results shows that more than half of adolescents had low category (53.1\%) in adolescents-fathers' attachment and medium category (51.3\%) in adolescents-mothers' attachment. Moreover, more than half of adolescents $(61.2 \%)$ had moderate category in reappraisal and more than one third of adolescents $(38.8 \%)$ had low category in suppression. Besides, more than half of adolescents had high category $(68.3 \%)$ in peer relationship and medium category $(57.1 \%)$ in online resilience. The result of regression test $\left(R^{2}=0.394\right)$ showed that adolescent's sex, per capita income, emotion regulation reaprraisal, and peer relationship have influence on adolescents' online resilience. The implications of the research results on how to increase online resilience discuss in this paper.
\end{abstract}

Keywords: adolescent, adolescent attachment to parents, emotion regulation, online resilience, peer relationship

\section{PENDAHULUAN}

Internet telah menjadi salah satu bagian kehidupan remaja saat ini. Hasil laporan survei nasional menunjukkan bahwa persentase remaja usia 10-14 tahun yang menjadi pengguna internet adalah sebesar 5,5 persen dan persentase remaja usia 15-19 tahun yang 
menjadi pengguna internet termasuk media sosial di dalamnya adalah 9,6 persen (APJII, 2020). Media ini sangat populer bagi anak dan remaja karena memungkinkan mereka berkomunikasi pada teman dan anggota keluarga, mengikuti figur publik dan membicarakannya kepada teman-teman, menambah teman baru maupun terhubung kembali dengan teman lama, serta mengikuti komunitas yang memiliki ketertarikan yang sama (Triastuti, Prabowo, \& Nurul, 2017). Di sisi lain, media sosial juga dapat mengakibatkan terjadinya perbandingan sosial, depresi, paparan konten yang tidak patut, dan perundungan siber (Nesi \& Prinstein, 2015; Wisniewski et al., 2015). Jika dilihat dari penduduk secara umum, sebanyak 49 persen penduduk Indonesia pernah diejek/dilecehkan di media sosial (APJII, 2018). Adapun survei nasional lainnya menunjukkan bahwa lebih dari separuh (58\%) anak-anak dan remaja Indonesia belum menyadari masalah perundungan siber. Selama tiga bulan terakhir saat survei dilakukan, perundungan siber telah dilaporkan terjadi pada 13 persen anak-anak dan remaja dengan 5 persen dari mereka telah mengalami perundungan siber lebih dari sekali (Gayatri et al., 2015). Dari berbagai kasus yang telah disebutkan, tampak bahwa remaja perlu mengembangkan kemampuan untuk menghadapi situasi, ancaman, atau risiko negatif dari aktivitas daring yang dilakukannya.

Salah satu kemampuan yang dapat dikembangkan remaja pengguna media sosial adalah online resilience (Hendriani, 2018; Wisniewski et al., 2015). Online resilience adalah kemampuan remaja dalam menghadapi keadaan sulit dan berbahaya di dunia online (d'Haenens et al., 2013). Online resilience dalam penelitian ini mengacu pada kemampuan remaja untuk menghadapi pengalaman tidak menyenangkan dari aktivitas online yang dilakukan di media sosial. Kemampuan ini membantu remaja mengalihkan emosi negatif akibat media sosial ke emosi netral/positif melalui berbagai cara seperti membicarakan masalahnya pada orang lain untuk mendapat dukungan emosi dan saran pemecahan masalah, serta melakukan koping strategi terfokus pada masalah seperti menghapus pesan, memblokir kontak, dan melaporkan pelaku (d'Haenens, Vandoninck, \& Donoso, 2013). Hasil empiris menunjukkan semakin tinggi tingkat resiliensi anak maka semakin rendah kasus perundungan dan perundungan siber. Remaja yang resilien memungkinkan remaja lebih tangguh jika diintimidasi, tidak melihat penindasan sebagai pengalaman yang menyakitkan, atau menjadi tidak menarik bagi perundung karena remaja resilien tidak memberikan reaksi yang diharapkan perundung (Hinduja \& Patchin, 2017). Online resilience dapat mengurangi efek psikologis negatif akibat adiksi internet dan paparan negatif di internet (Wisniewski et al., 2015). Menurut d'Haenens et al. (2013), faktor yang dapat memengaruhi online resilience pada remaja adalah jenis kelamin, usia, status sosial ekonomi, efikasi diri, masalah psikologis, dukungan dari teman dan guru, keterlibatan orang tua, dan aktivitas daring. Studi empiris mengenai online resilience masih sangat terbatas sehingga online resilience dalam tulisan ini seringkali merujuk pada konsep dasar online resilience, yaitu resiliensi. Beberapa penelitian sebelumnya mengantarkan bahwa kelekatan remaja pada orang tua, regulasi emosi, dan hubungan persahabatan berhubungan dengan resiliensi (Erdem, 2017; Graber et al., 2016; Widuri, 2012).

Kelekatan (attachment) adalah ikatan emosional yang sangat kuat antara individu dengan individu lainnya (Arsmden \& Greenberg, 1987). Kelekatan remaja-orang tua dalam penelitian ini mengacu pada ikatan emosional yang dibentuk remaja dan orang tuanya melalui tingginya interaksi komunikasi dan kepercayaan, serta rendahnya pengasingan. Remaja Sekolah Menengah Atas (SMA) yang memiliki kelekatan baik pada ayah maupun ibunya akan memiliki resiliensi yang lebih baik (Erdem, 2017). Tingginya kelekatan atau kelekatan aman yang terjalin antara anak dengan orang tuanya menjadi fondasi dalam regulasi emosi anak (Megawangi, 2015).

Sementara itu, regulasi emosi adalah serangkaian upaya yang dilakukan untuk memengaruhi emosi yang dialami dan diekspresikan (Gross, 1999). Regulasi emosi dalam penelitian ini didefinisikan sebagai upaya yang dilakukan remaja untuk saat mengalami emosi, yaitu dengan upaya penilaian ulang atau penekanan emosi. Regulasi emosi penilaian ulang berfokus pada cara pikir kognitif dalam mengubah situasi stres sedangkan regulasi penekanan emosi adalah penyesuaian emosi dengan menghambat/menahan diri dalam mengekspresikan emosi (Gross, 2001). Regulasi emosi penilaian ulang membantu dalam meningkatkan resiliensi (Karreman \& Vingerhoets, 2017). Tidak hanya itu, regulasi emosi juga dibutuhkan dalam menjalin hubungan sosial. Menurut Schwarz, Stutz, dan Ledermann (2012), remaja yang memiliki kemampuan mengelola emosi cenderung memiliki teman yang dapat mendukung persahabatan, memberikan bantuan, 
memberikan intimasi, dan memberikan perasaan aman.

Teman sebaya diketahui membantu meningkatkan resiliensi remaja melalui fungsi positif pertemanan (Graber et al., 2016). Hal ini mengindikasikan bahwa kualitas dalam hubungan persahabatan yang terjalin dapat berperan dalam membangun online resilience remaja. Hubungan persahabatan dalam penelitian ini didefinisikan sebagai derajat keberfungsian seorang teman terhadap suatu individu yang diukur melalui enam dimensi fungsi pertemanan, yaitu stimulasi persahabatan, pemberian bantuan, kedekatan, ikatan yang dapat diandalkan, validasi diri, dan keamanan emosi.

Dengan demikian, dapat diduga bahwa tingginya kelekatan antara remaja-orang tua, regulasi emosi tipe penilaian ulang, dan hubungan persahabatan yang berfungsi optimal memengaruhi online resilience pada remaja. Studi terkait resiliensi dengan kelekatan (Bender \& Ingram, 2018; Erdem, 2017; He, Chen, Fan, Cai, \& Hao, 2018), regulasi emosi (Karreman \& Vingerhoets, 2017; Mestre, Núñez-Lozano, Gómez-Molinero, Zayas, \& Guil, 2017, Sukmaningpraja \& Santhoso, 2017; Widuri, 2012), dan hubungan persabatan (Australian Institute of Family Studies, 2019; Graber et al., 2016; van Harmelen et al., 2017) telah dilakukan meski secara terpisah.

Akan tetapi, penelitian terkait online resilience masih sangat terbatas. Literatur sebelumnya menyatakan bahwa pokok penting dalam menumbuhkan online resilience adalah pengelolaan risiko digital, koping komunikatif dan proaktif, lingkungan tumbuh kembang, dan optimalisasi pengasuhan (Hendriani, 2017). Faktor pengasuhan seperti gaya pengasuhan otoritatif ditemukan berperan dalam pembentukan online resilience pada mahasiswa (Firdaus \& Kelly, 2019). Adapun keterlibatan orang tua, teman, dan guru seperti pemberian saran dalam menggunakan internet dengan aman diketahui dapat berperan dalam peningkatan online resilience anak dan remaja. Jika seorang anak mampu merespons secara proaktif dengan fokus memecahkan masalah atau mentransfer emosi negatif ke dalam perasaan positif atau netral, anak tersebut mampu mengatasi pengalaman tidak menyenangkan dari penggunaan internet (d'Haenens et al., 2013). Berdasarkan hal tersebut, peneliti menduga belum tersedia bukti empiris yang menjelaskan online resilience ditinjau dari kelekatan remaja-orang tua, regulasi emosi, dan hubungan persahabatan pada remaja. Tujuan penelitian ini adalah untuk mengidentifikasi karakteristik remaja, karakteristik keluarga, kelekatan remaja-orang tua, regulasi emosi, hubungan persahabatan, dan online resilience; dan menganalisis pengaruh karakteristik remaja, karakteristik keluarga, kelekatan remaja-orang tua, regulasi emosi, dan hubungan persahabatan terhadap online resilience pada remaja pengguna media sosial.

\section{METODE}

Penelitian ini menggunakan pendekatan kuantitatif dan desain eskplanatori. Kota Bogor dipilih secara purposive sebagai lokasi penelitian dengan pertimbangan bahwa Kota Bogor merupakan daerah pengakses media sosial terbanyak di Jawa Barat, setelah Kota Bandung dan Bekasi (Parno, 2019). Waktu pengambilan data dari penentuan sampel hingga pengisian kuesioner adalah Maret hingga April 2020. Remaja yang menjadi contoh dalam penelitian ini diambil secara non probability sampling dengan teknik purposive sampling berdasarkan kriteria yang ditetapkan, yaitu berusia 15-18 tahun, tinggal bersama orang tua lengkap, dan menggunakan media sosial. Usia 15-18 tahun dipilih untuk menyesuaikan usia siswa remaja SMA. Remaja yang memiliki dan tinggal bersama orang tua lengkap dipilih menjadi kriteria agar variabel kelekatan remaja-orang tua dapat diukur. Remaja yang menggunakan media sosial dipilih agar dapat menggambarkan online resilience yang dimiliki remaja. Jumlah remaja yang menjadi responden penelitian adalah 245 orang. Setelah proses pembersihan, sebanyak 21 data dieliminasi karena tidak memenuhi kriteria sehingga menyisakan 224 data yang dapat diolah lebih lanjut.

Variabel yang diteliti adalah karakteristik remaja (usia dan jenis kelamin), karakteristik keluarga (usia, pendidikan, dan status pekerjaan orang tua, serta besar keluarga dan pendapatan per kapita), kelekatan remaja-orang tua, regulasi emosi, hubungan persahabatan, dan online resilience. Jenis skala data usia, jenis kelamin, dan status pekerjaan orang tua adalah nominal. Adapun jenis skala data usia remaja, usia orang tua, lama pendidikan orang tua, besar keluarga, dan pendapatan per kapita adalah rasio.

Kelekatan remaja-orang tua diukur menggunakan modifikasi instrumen Revised Inventory of Parent and Peer Attachment (IPPA) yang dikembangkan oleh Armsden dan Greenberg (1987). R-IPPA terdiri atas tiga dimensi, yaitu kepercayaan, komunikasi, dan 
pengasingan. Kuesioner ini menggunakan 25 butir pernyataan untuk mengukur kelekatan remaja-ibu dan 25 butir pernyataan untuk mengukur kelekatan remaja-ayah dan skala likert ( 1 =sangat tidak sesuai; $2=$ tidak sesuai; $3=$ sesuai; $4=$ sangat sesuai). Nilai reliabilitas (cronbach's alpha) kuesioner kelekatan remajaibu adalah 0,937 dan kelekatan remaja-ayah adalah 0,931. Dalam pengukuran total kelekatan remaja-orang tua, skor dimensi pengasingan di-invers $(1=4,2=3,3=2,4=1)$ kemudian dijumlahkan dengan skor dimensi komunikasi dan skor kepercayaan. Semakin tinggi skor yang diperoleh, semakin tinggi kelekatan remaja-orang tua.

Regulasi emosi remaja diukur menggunakan modifikasi instrumen Emotion Regulation Questionnaire (Gross \& John, 2003). Kuesioner terdiri atas dimensi penilaian ulang kognitif (6 butir pernyataan) dan penekanan emosi (4 butir pernyataan). Kuesioner menggunakan pilihan jawaban 1=hampir tidak pernah, 2=jarang, $3=$ sering, dan $4=$ hampir selalu. Nilai reliabilitas (cronbach's alpha) kuesioner regulasi emosi untuk penilaian ulang dan penekanan emosi berturut-turut adalah 0,797 dan 0,653. Skor dinilai terpisah sesuai dengan dimensi. Semakin tinggi skor satu dimensi, semakin tinggi upaya remaja dalam menggunakan upaya dimensi tersebut.

Hubungan persahabatan diukur menggunakan modifikasi instrumen McGill Friendship Questionnaire-Friend's Functions Short Version (Mendelson \& Aboud, 1999). Kuesioner ini menggunakan 30 pernyataan dengan pilihan jawaban skala dari $0=$ tidak pernah hingga 8=selalu. Reliabilitas (cronbach's alpha) kuesioner ini adalah 0,973. Skor dihitung secara komposit dan tingginya skor yang diperoleh menunjukkan tingginya derajat keberfungsian teman atau kualitas persahabatan yang dimiliki.

Online resilience diukur menggunakan modifikasi instrumen Connor-Davidson Resilience Scale (Connor \& Davidson, 2003). Kuesioner ini terdiri atas 25 butir pernyataan mengenai resiliensi secara umum kemudian dimodifikasi dalam konteks daring. Kuesioner menggunakan pilihan jawaban skala Likert ( 1 =hampir tidak pernah; $2=$ jarang; $3=$ sering; 4=hampir selalu). Nilai reliabilitas (cronbach's alpha) kuesioner ini adalah 0,896. Total skor tinggi yang didapatkan menunjukkan tingginya kemampuan menghadapi pengalaman tidak menyenangkan di dunia online.

Data yang diperoleh diolah melalui enam tahapan, yaitu proses pemasukan, penyuntingan, pengodean, pemberian skor, pengecekan ulang, dan analisis serta interpretasi data. Pemasukan data dilakukan dengan menggunakan WPS Office dan analisis data dilakukan dengan Statistical Package for Social Science (SPSS) versi 25.0. Pengolahan dan analisis data diperoleh dengan menggunakan uji deskriptif dan uji regresi. Total skor setiap variabel diindeks dan dikategorikan menjadi rendah $(<60)$, sedang $(60-80)$, dan tinggi (>80). Uji deskriptif seperti jumlah, persentase, nilai rataan, standar deviasi, nilai minimum, dan nilai maksimum digunakan untuk mengidentifikasi hasil pengukuran tiap variabel. Uji regresi digunakan untuk mengukur pengaruh antarvariabel. Sebelum dilakukan uji regresi, dilakukan uji asumsi klasik sebagai syarat kelayakan data dapat dianalisis dengan menggunakan regresi linear berganda.

\section{HASIL}

\section{Karakteristik Remaja dan Keluarga}

Jenis kelamin remaja dalam penelitian ini sebagian besar perempuan $(67,7 \%)$ dan sisanya laki-laki (33,0\%). Jika dilihat berdasarkan usia, mayoritas remaja berusia 16 tahun $(45,1 \%)$, kemudian disusul remaja usia 17 tahun (35,3\%), 15 tahun (14,7\%), dan 18 tahun (4,9\%). Rata-rata usia remaja adalah 16,30 tahun. Sebanyak 42.4 persen remaja berasal dari keluarga dengan besar keluarga 4 orang.dan lebih dari sepertiga remaja berasal dari keluarga dengan 5 orang anggota keluarga. Rata-rata besar keluarga adalah 4,73 orang (Tabel 1).

Hasil penelitian menunjukkan, rata-rata usia ayah adalah 49,97 tahun dan ibu adalah 45,16 tahun. Rata-rata lama pendidikan ayah adalah 13,36 tahun dan persentase lulusan pendidikan terbesar adalah tamat SMA $(39,7 \%)$ dan strata 1 (20,5\%). Rata-rata lama pendidikan ibu adalah 12,44 tahun dan persentase lulusan pendidikan terbesar adalah tamat SMA $(40,2 \%)$ dan strata $1(15,2 \%)$. Selain itu, sebanyak 96,4 persen ayah bekerja dan sisanya tidak bekerja. Persentase pekerjaan terbesar yang dimiliki ayah adalah pegawai swasta $(28,6 \%)$ dan PNS $(12,9 \%)$, sedangkan sebanyak 64,7 persen ibu tidak bekerja dan sisanya bekerja. Persentase pekerjaan terbesar yang dimiliki ibu adalah wirausaha/pedagang $(11,2 \%)$ dan PNS $(8,9 \%)$. Pendapatan per kapita minimum dari keluarga responden yang ditemukan adalah Rp50.000,00 dan maksimum adalah Rp20.000.000,00. Mayoritas remaja (83,0\%) berasal dari keluarga dengan pendapatan per kapita di atas garis kemiskinan Kota Bogor. 
Tabel 1 Nilai minimum, nilai maksimum, rataan, dan standar deviasi karakteristik keluarga

\begin{tabular}{|c|c|c|c|}
\hline Karakteristik & Minimum & Maksimum & $\begin{array}{c}\text { Rata-rata } \\
\pm \text { SD }\end{array}$ \\
\hline $\begin{array}{l}\text { Usia ayah } \\
\text { (tahun) }\end{array}$ & 37 & 73 & $\begin{array}{c}49,97 \pm \\
6,39\end{array}$ \\
\hline $\begin{array}{l}\text { Lama } \\
\text { pendidikan } \\
\text { ayah (tahun) }\end{array}$ & 2 & 21 & $\begin{array}{c}13,36 \pm \\
3,41\end{array}$ \\
\hline $\begin{array}{l}\text { Usia } \\
\text { ibu(tahun) }\end{array}$ & 28 & 59 & $\begin{array}{c}45,16 \pm \\
5,51\end{array}$ \\
\hline $\begin{array}{l}\text { Lama } \\
\text { pendidikan } \\
\text { ibu(tahun) }\end{array}$ & 0 & 21 & $\begin{array}{c}12,44 \pm \\
3,48\end{array}$ \\
\hline $\begin{array}{l}\text { Besar } \\
\text { keluarga } \\
\text { (orang) }\end{array}$ & 3 & 8 & $\begin{array}{c}4,73 \pm \\
1,02\end{array}$ \\
\hline $\begin{array}{l}\text { Pendapatan } \\
\text { keluarga per } \\
\text { kapita } \\
\text { (Rp/bulan) }\end{array}$ & 50.000 & 20.000 .000 & $\begin{array}{c}1.739 .31 \\
6,384 \pm \\
2.084 .96 \\
0,23\end{array}$ \\
\hline
\end{tabular}

Keterangan: $\mathrm{SD}=$ standar deviasi

\section{Kelekatan Remaja-Orang Tua}

Secara keseluruhan, sesuai pada hasil yang tersaji pada Tabel 2, mayoritas remaja memiliki kelekatan kategori rendah-sedang $(53,1 \%$ dan $40,6 \%)$ dengan ayah serta kelekatan kategori sedang-rendah ( $51,3 \%$ dan $27,7 \%$ ) dengan ibu. Artinya, remaja dalam penelitian ini memiliki kelekatan yang lebih tinggi dengan ibu dibandingkan dengan ayahnya. Hal ini diduga karena lebih dari enam puluh persen ibu bekerja sebagai ibu rumah tangga sehingga memiliki peran dan waktu pengasuhan yang lebih dominan dibandingkan dengan ayah sehingga remaja lebih dekat dan terbuka dengan ibu.

Kelekatan Remaja-Ayah. Hasil penelitian menunjukkan bahwa sebanyak lima dari sepuluh remaja memiliki kelekatan remaja-ayah terkategori rendah $(53,1 \%)$ dengan rataan indeks 56,82 (Tabel 2). Sebanyak 42 persen remaja memiliki dimensi kepercayaan kategori sedang, ditandai dengan ayah yang sering memercayai penilaian remaja $(51,3 \%)$ dan remaja hampir selalu memercayai ayah $(52,7 \%)$. Akan tetapi, sebagian besar remaja memiliki dimensi komunikasi terkategori rendah dengan ayahnya $(75,5 \%)$. Remaja jarang memberi tahu ayah mengenai masalah/kesulitan yang remaja miliki $(46,4 \%)$, ayah jarang membantu remaja untuk menceritakan permasalahan remaja $(45,1 \%)$, dan remaja jarang mengandalkan ayah ketika remaja membutuhkan bantuan untuk melepaskan hal yang mengganjal di hati $(53,1 \%)$. Berdasarkan hal tersebut, tampaknya remaja enggan untuk menjalin kedekatan dengan ayah seperti layaknya remaja menjalin kedekatan ibu, tetapi bukan berarti remaja menyimpan amarah dengan ayah. Pada dimensi pengasingan, hampir separuh remaja $(46,9 \%)$ merasa malu jika harus curhat kepada ayah, tetapi di sisi lain, remaja juga jarang merasa marah kepada ayah $(56,7 \%)$.

Kelekatan Remaja-lbu. Hasil penelitian menemukan bahwa lebih dari setengah remaja memiliki kelekatan remaja-ibu kategori sedang $(51,3 \%)$ dengan rataan indeks 68,75 . Dimensi kepercayaan remaja dengan ibunya banyak terkategori sedang $(44,6 \%)$ (Tabel 2). Hal ini ditandai dengan remaja hampir selalu merasa ibunya telah melakukan peran yang baik $(67,0 \%)$, remaja hampir selalu memercayai ibu $(62,1 \%)$, dan ibu sering memercayai penilaian remaja $(58 \%)$. Selain itu, hampir separuh remaja $(45,1 \%)$ memiliki dimensi komunikasi kategori rendah dengan ibunya. Remaja jarang memberitahu ibu mengenai masalah dan kesulitan yang dimilikinya $(36,2 \%)$, tetapi remaja sering dapat mengandalkan ibu ketika remaja membutuhkan bantuan untuk melepaskan hal yang mengganjal di hati $(40,6 \%)$. Pada dimensi pengasingan, remaja jarang merasa malu jika harus curhat kepada ibu $(37,1 \%)$ dan 57,1 persen remaja jarang merasa marah kepada ibu.

\section{Regulasi Emosi}

Secara keseluruhan remaja lebih banyak menggunakan penilaian ulang dibandingkan penekanan emosi sebagai upaya meregulasi emosinya. Pada masa remaja, fungsi kognitif telah berkembang lebih baik dibandingkan masa perkembangan sebelumnya sehingga tidak heran jika remaja telah mampu melakukan regulasi emosi penilaian ulang yang melibatkan fungsi kognitif. Remaja yang mampu menggunakan cara pikir kognitif dalam regulasi emosi ditandai dengan pengubahan situasi tertentu untuk mengurangi dampak emosional yang tidak diinginkan.

Penilaian Ulang. Tabel 2 menunjukkan bahwa regulasi emosi penilaian ulang remaja terkategori sedang $(61,2 \%)$. Hal ini ditandai dengan remaja sering mengubah cara berpikirnya agar dapat mengontrol perasaan $(65,6 \%)$, dan sering mengubah sudut pandang ketika remaja menghadapi permasalahan agar dapat mengurangi perasaan negatif $(63,8 \%)$.

Penekanan Emosi. Regulasi emosi penekanan emosi remaja paling banyak masuk dalam kategori rendah $(38,8 \%)$. Akan tetapi, tidak jauh dari itu sebanyak 34,4 persen remaja memiliki 
penekanan emosi kategori sedang. Hal ini dicirikan dengan remaja yang hampir selalu memendam perasaan $(42,0 \%)$ dan sering memastikan untuk tidak menunjukkan perasaan negatif $(52,2 \%)$.

\section{Hubungan Persahabatan}

Tabel 2 menunjukkan bahwa sebagian remaja $(68,3 \%)$ memiliki hubungan persahabatan dengan kategori tinggi. Tingginya skor hubungan persahabatan dibandingkan kelekatan remaja-orang tua mengindikasikan remaja lebih dekat dengan teman sebaya dibandingkan dengan orang tuanya. Hal ini disebabkan karena di usia belasan tahun, remaja telah mengembangkan hubungan yang lebih dekat dengan teman sebayanya. Lebih lanjut, dimensi yang memiliki rataan indeks tertinggi adalah ikatan yang andal. Hal ini mengindikasikan bahwa remaja memiliki rasa percaya terhadap keberlanjutan ikatan persahabatan yang telah terjalin.

Stimulasi Persahabatan. Dimensi ini merujuk pada aktivitas yang dilakukan bersama-sama dan merangsang kesenangan dan hiburan. Mayoritas remaja $(79,9 \%)$ memiliki dimensi stimulasi persahabatan terkategori tinggi. Rataan indeks dimensi ini adalah 87,26. Bentuk stimulasi persahabatan misalnya selalu asyik diajak berbicara $(53,1 \%)$
Pemberian Bantuan. Dimensi ini merujuk pada penyediaan petunjuk, informasi, saran, dan bentuk bantuan konkret lainnya yang diperlukan untuk memenuhi kebutuhan. Lebih dari separuh remaja $(64,7 \%)$ memiliki dimensi pemberian bantuan terkategori tinggi. Rataan indeks dimensi ini adalah 82,54. Bentuk pemberian bantuan misalnya selalu membantu remaja melakukan berbagai macam hal $(37,5 \%)$ dan selalu akan meminjamkan barangnya ketika remaja membutuhkannya $(41,5 \%)$.

Intimasi/Kedekatan. Dimensi ini menggambarkan kepekaan terhadap keadaan pihak lain dan memberikan penerimaan pada kepribadian apa adanya. Hasil menunjukkan bahwa lebih dari separuh remaja $(59,4 \%)$ memiliki intimasi terkategori tinggi. Rataan indeks dimensi ini adalah 79,30. Bentuk intimasi misalnya selalu menjadi tempat yang nyaman untuk membicarakan hal pribadi $(40,6 \%)$.

Ikatan yang Andal. Dimensi ini mendeskripsikan keberadaan teman yang dapat dipercaya dan loyalitas teman secara berkelanjutan. Mayoritas remaja (79,5\%) memiliki dimensi ikatan yang andal terkategori tinggi. Rataan indeks dimensi ini adalah 88,25. Bentuk ikatan yang andal misalnya selalu tetap menjadi teman meski lama tidak bertemu $(54,9 \%)$.

Tabel 2 Kategori, nilai minimum-maksimum, rataan, dan standar deviasi variabel kelekatan remajaorang tua, regulasi emosi, hubungan persahabatan, dan online resilience

\begin{tabular}{lccccc}
\hline \multirow{2}{*}{ Variabel } & \multicolumn{3}{c}{ Kategori $(\%)$} & Min-Maks & Rata-rata \pm SD \\
\cline { 2 - 4 } & Rendah & Sedang & Tinggi & & \\
\hline Kelekatan remaja-ayah & 53,1 & 40,6 & 6,3 & $6,67-93,33$ & $56,82 \pm 17,63$ \\
Kepercayaan & 33,5 & 42,0 & 24,6 & $6,67-100,00$ & $67,39 \pm 19,63$ \\
Komunikasi & 75,0 & 20,5 & 4,5 & $0,00-85,18$ & $46,74 \pm 20,39$ \\
Pengasingan & 71,9 & 25,9 & 2,2 & $0,00-100,00$ & $45,68 \pm 19,49$ \\
Kelekatan remaja-ibu & 27,7 & 51,3 & 21,0 & $12,00-100,00$ & $68,75 \pm 16,97$ \\
Kepercayaan & 15,6 & 44,6 & 39,7 & $10,00-100,00$ & $75,43 \pm 17,27$ \\
Komunikasi & 45,1 & 33,5 & 21,4 & $0,00-100,00$ & $63,12 \pm 20,73$ \\
Pengasingan & 89,7 & 8,9 & 1,3 & $0,00-88,89$ & $33,95 \pm 18,55$ \\
Regulasi emosi & & & & & \\
Penilaian ulang & 17,4 & 61,2 & 21,4 & $11,11-100,00$ & $69,12 \pm 15,00$ \\
Penekanan emosi & 38,8 & 34,4 & 26,8 & $25,00-100,00$ & $67,03 \pm 17,15$ \\
Hubungan persahabatan & 6,3 & 25,4 & 68,3 & $23,75-100,00$ & $83,21 \pm 13,75$ \\
$\quad$ Stimulasi persahabatan & 4,0 & 16,1 & 79,9 & $22,50-100,00$ & $87,26 \pm 13,47$ \\
Bantuan & 8,9 & 26,3 & 64,7 & $22,50-100,00$ & $82,54 \pm 14,24$ \\
Intimasi/kedekatan & 15,2 & 25,4 & 59,4 & $10,00-100,00$ & $79,30 \pm 18,30$ \\
Ikatan yang andal & 4,9 & 15,6 & 79,5 & $20,00-100,00$ & $88,25 \pm 14,08$ \\
Validasi diri & 8,9 & 25,9 & 65,2 & $22,50-100,00$ & $81,99 \pm 13,94$ \\
$\quad$ Keamanan emosi & 12,5 & 27,7 & 59,8 & $15,00-100,00$ & $79,93 \pm 16,48$ \\
Online resilience & 33,0 & 57,1 & 9,8 & $22,66-100,00$ & $64,75 \pm 12,27$ \\
\hline
\end{tabular}

Keterangan: $\mathrm{Min}=$ minimum; Maks=maksimum; $\mathrm{SD}=$ standar deviasi 
Validasi Diri. Validasi diri mengacu pada keberadaan teman yang mampu meyakini, menyetujui, menyemangati, mendengarkan, dan mempertahankan kesan sebagai diri yang memiliki kompetensi dan berharga. Lebih dari separuh remaja $(65,2 \%)$ memiliki dimensi validasi diri terkategori tinggi. Rataan indeks dimensi ini adalah 81,99. Bentuk validasi misalnya selalu membuat remaja merasa bisa melakukan sesuatu dengan baik (36,6\%).

Keamanan Emosi. Keamanan emosi merujuk pada rasa nyaman dan keyakinan yang diberikan teman dalam situasi yang mengancam. Hasil penelitian menunjukkan bahwa lebih dari separuh remaja $(59,8 \%)$ memiliki dimensi keamanan emosi terkategori tinggi. Rataan indeks dimensi ini adalah 79,93. Bentuk keamanan emosi misalnya selalu bisa membuat remaja merasa lebih baik ketika remaja kesal $(34,8 \%)$.

\section{Online Resilience}

Berdasarkan Tabel 2, dapat dilihat bahwa lebih dari separuh online resilience remaja berada di tingkat sedang $(57,1 \%)$. Jika dilihat dari sebaran jawaban remaja, dapat diketahui bahwa remaja sering mampu menangani segala permasalahan di media sosial $(53,1 \%)$, sering mampu mengatasi stres atau tekanan dalam menghadapi permasalahan di media sosial $(61,2 \%)$, sering mampu segera bangkit kembali setelah mengalami kesulitan atau permasalahan di media sosial $(63,8 \%)$, dan sering dapat mengatasi perasaan yang tidak menyenangkan saat menggunakan media sosial $(59,4 \%)$. Persentase remaja dengan online resilience yang berada di tingkat rendah mencapai 33 persen. Rendahnya online resilience remaja ditandai dengan remaja yang jarang mengetahui harus kemana saat meminta bantuan jika menemui masalah di media sosial $(32,1 \%)$. Hal ini mengindikasikan besarnya peluang bahaya yang dapat diterima remaja saat menggunakan media sosial karena tidak diiringi dengan kecakapan online resilience yang tinggi.

Tabel 3 Hasil uji pengaruh karakteristik remaja, karakteristik keluarga, kelekatan remaja-orang tua, regulasi emosi, dan hubungan persahabatan terhadap online resilience

\begin{tabular}{|c|c|c|c|c|}
\hline \multirow[t]{2}{*}{ Variabel } & \multicolumn{2}{|c|}{$\begin{array}{l}\text { Koefisien tidak } \\
\text { terstandarisasi }\end{array}$} & \multirow{2}{*}{$\begin{array}{c}\text { Koefisien } \\
\text { terstandarisasi } \\
\beta\end{array}$} & \multirow[t]{2}{*}{ Sig. } \\
\hline & $\mathrm{B}$ & Std. Error & & \\
\hline Konstanta & 7,796 & 17,151 & & 0,650 \\
\hline \multicolumn{5}{|l|}{ Karakteristik remaja } \\
\hline Jenis kelamin remaja ( 0 =laki-laki; $1=$ perempuan) & $-4,079$ & 1,490 & $-0,157$ & $0,007^{* *}$ \\
\hline Usia remaja (tahun) & 0,777 & 0,867 & 0,049 & 0,371 \\
\hline \multicolumn{5}{|l|}{ Karakteristik keluarga } \\
\hline Usia ayah (tahun) & $-0,200$ & 0,137 & $-0,104$ & 0,147 \\
\hline Pendidikan ayah (tahun) & $-0,051$ & 0,267 & $-0,014$ & 0,850 \\
\hline Pekerjaan ayah ( 0 =tidak bekerja; $1=$ bekerja) & $-3,763$ & 3,662 & $-0,057$ & 0,305 \\
\hline Usia ibu (tahun) & 0,124 & 0,159 & 0,056 & 0,435 \\
\hline Pendidikan ibu (tahun) & 0,230 & 0,265 & 0,065 & 0,387 \\
\hline Pekerjaan ibu ( 0 =tidak bekerja; 1 =bekerja) & 0,119 & 1,442 & 0,005 & 0,934 \\
\hline Besar keluarga & 0,538 & 0,651 & 0,045 & 0,409 \\
\hline Pendapatan per kapita (Rupiah) & $7,78 \times 10^{-4}$ & 0,000 & 0,132 & $0,023^{*}$ \\
\hline \multicolumn{5}{|l|}{ Kelekatan remaja-orang tua } \\
\hline Kelekatan remaja-ayah & $-0,048$ & 0,044 & $-0,068$ & 0,277 \\
\hline Kelekatan remaja-ibu & 0,028 & 0,046 & 0,039 & 0,541 \\
\hline \multicolumn{5}{|l|}{ Regulasi emosi } \\
\hline Regulasi emosi (penilaian ulang) & 0,423 & 0,053 & 0,517 & $0,000^{* *}$ \\
\hline Regulasi emosi (penekanan emosi) & 0,045 & 0,045 & 0,063 & 0,327 \\
\hline Hubungan persahabatan & 0,210 & 0,050 & 0,235 & $0,000^{* *}$ \\
\hline Adjusted R square & & & 0,394 & \\
\hline R square & & & 0,435 & \\
\hline $\mathrm{F}$ & & & 10,668 & \\
\hline Sig & & & 0,000 ** & \\
\hline
\end{tabular}

Keterangan: ${ }^{* *}$ signifikan pada $p<0,01$; ${ }^{*}$ signifikan pada $p<0,05$; $B=$ koefisien regresi belum terstandar; $\beta=k o e f i s i e n$ regresi sudah terstandar 


\section{Pengaruh Karakteristik Remaja, Karakteristik Keluarga, Kelekatan Remaja- Orang Tua, Regulasi Emosi, dan Hubungan Persahabatan terhadap Online Resilience}

Model yang digunakan untuk menganalisis pengaruh karakteristik keluarga, kelekatan remaja-orang tua, regulasi emosi, dan hubungan persahabatan terhadap online resilience pada remaja pengguna media sosial signifikan pada $p<0,000$, artinya model regresi dengan metode enter ini memiliki nilai signifikansi yang baik. Hasil uji ini menunjukkan adanya pengaruh simultan (bersama-sama) variabel yang terdapat dalam model terhadap online resilience. Nilai adjusted $\mathrm{R}^{2}$ dalam model regresi ini adalah 0,394. Hal ini menandakan bahwa 39,4 persen variabel online resilience dapat dipengaruhi oleh variabel yang diteliti. Jenis kelamin remaja $(B=-4,079)$ berpengaruh signifikan $(p<0,01)$ terhadap online resilience. Hal ini berarti laki-laki memiliki online resilience yang lebih tinggi dari perempuan. Pendapatan per kapita $\left(B=7,78 \times 10^{-4}\right)$ berpengaruh signifikan positif $(p<0,05)$ terhadap online resilience. Artinya, setiap kenaikan satu rupiah pendapatan per kapita akan menaikkan online resilience sebesar $7,78 \times 10^{-4}$ satuan. Regulasi emosi peninjauan ulang $(B=0,423)$ memiliki pengaruh positif signifikan $(p<0,01)$ terhadap online resilience. Artinya, setiap kenaikan satu satuan regulasi emosi peninjauan ulang akan menaikkan online resilience sebesar 0,423 satuan. Hubungan persahabatan $(B=0,210)$ berpengaruh signifikan positif $(p<0,01)$ terhadap online resilience. Hal ini menunjukkan bahwa setiap kenaikan satu satuan hubungan persahabatan akan menaikkan online resilience sebesar 0,210 satuan (Tabel 3).

\section{PEMBAHASAN}

Online resilience sebagai salah satu kecakapan hidup diperlukan remaja dalam menggunakan media sosial agar tangguh dan dapat mengatasi berbagai dinamika di media sosial. Akan tetapi, dalam penelitian ini terbukti bahwa tidak sampai 10 persen remaja yang memiliki online resilience kategori tinggi. Hal ini menandakan bahwa terdapat lebih dari 90 persen remaja berpeluang untuk meningkatkan online resilience-nya menjadi lebih baik lagi. Lebih lanjut, hasil uji regresi pada penelitian ini menunjukkan bahwa jenis kelamin, pendapatan per kapita, regulasi emosi penilaian ulang, dan hubungan persahabatan memberi kontribusi terhadap peningkatan online resilience.

Jenis kelamin berpengaruh signifikan negatif terhadap online resilience. Artinya, remaja laki- laki memiliki online resilience lebih tinggi dibandingkan dengan perempuan. Hasil ini mendukung penelitian sebelumnya yang mengemukakan adanya kontribusi jenis kelamin remaja terhadap resiliensi (Maesaroh et al., 2019; van Harmelen et al., 2017). Kepercayaan diri yang lebih tinggi pada laki-laki dalam keterampilan mengatur emosi pada umumnya dapat menunjukkan upaya aktif dan tekad yang lebih besar untuk mengupayakan strategi-strategi dalam mengatasi kejadian buruk dibandingkan perempuan (Perchtold et al., 2019). Hal ini mengindikasikan alasan lakilaki dapat memiliki online resilience yang lebih tinggi, yaitu jika laki-laki mengalami masalah di media sosial, laki-laki dapat fokus mengarahkan diri untuk mengatasi masalah serta tidak larut terbawa perasaan. Hal ini didukung dengan studi sebelumnya (Hou et al., 2017) yang menunjukkan bahwa perempuan mengalami masalah penggunaan media sosial yang lebih tinggi dibandingkan laki-laki. Remaja perempuan lebih sering memikirkan media sosial meski sedang tidak menggunakannya.

Pendapatan per kapita berpengaruh signifikan positif terhadap online resilience. Hal ini berarti keadaan ekonomi keluarga turut berperan dalam pembentukan online resilience remaja. Tampaknya keadaan ekonomi yang lebih tinggi memungkinkan akses pengetahuan mengenai strategi mengatasi masalah di dunia daring yang lebih baik. Hasil penelitian yang ditemukan oleh Vissenberg dan d'Haenens (2020) menunjukkan bahwa sebanyak 44.4 persen anak muda usia 13-21 tahun yang berasal dari status sosial ekonomi yang rendah lebih memilih diam saat mengalami emosi negatif dalam pengalaman daring yang berisiko. Adapun 72.9 persen anak muda yang berasal dari status sosial ekonomi yang tinggi lebih banyak mengomunikasikan permasalahannya untuk mencari bantuan dalam mengatasi persoalan secara efektif.

Pada penelitian ini, kelekatan remaja-orang tua tidak memberi pengaruh terhadap online resilience. Temuan ini tidak sejalan dengan Erdem (2017), yaitu kelekatan remaja-orang tua berpengaruh nyata terhadap resiliensi remaja. Jika ditinjau dari dimensinya, remaja dalam penelitian ini memiliki komunikasi yang rendah baik pada ayah maupun ibunya. Angka ini tidak sebanding dengan skor dimensi kepercayaan yang lebih tinggi baik pada ayah maupun ibu remaja. Artinya, meskipun remaja menaruh kepercayaan pada orang tua, remaja tidak berkomunikasi cukup baik pada orang tuanya. Perbedaan jenis media sosial yang digunakan antara orang tua dengan remaja diduga 
menyebabkan rendahnya komunikasi antara remaja dengan orang tua. Sebagai contoh, remaja lebih banyak menggunakan Instagram sedangkan orang dewasa lebih banyak menggunakan Facebook (Susilo, 2018). Orang tua yang kurang memahami dunia media sosial yang digunakan anaknya bisa jadi kurang memahami persoalan dan strategi pemecahan masalah yang dihadapi remaja dalam menggunakan media sosial. Senada dengan hal tersebut, hasil penelitian Bradbury, Dubow, dan Domoff (2018) menunjukkan bahwa bila dibandingkan orang tua, saran strategis dari teman sebaya lebih berperan dalam membantu remaja mengatasi perlakuan agresif daring yang dirasakan remaja.

Regulasi emosi dimensi penilaian ulang berpengaruh sangat signifikan positif terhadap online resilience. Remaja yang memiliki kemampuan regulasi emosi dengan baik mampu tenang untuk mengarahkan kemampuan otak (kognitif) untuk menyelesaikan masalah dan tidak terjebak dalam situasi emosional (Goleman, 2018). Kemampuan ini mengisyaratkan alasan regulasi emosi dimensi penekanan emosi tidak berpengaruh signifikan terhadap online resilience. Penekanan emosi hanya fokus pada pengaturan emosi dan tidak melakukan upaya penyelesaian masalah media sosial secara langsung. Adapun regulasi emosi dimensi penilaian ulang dapat mendorong pemecahan masalah di media sosial dengan langkah strategis seperti menghapus pesan yang tidak diinginkan, memblok kontak, dan melaporkan pelaku. Remaja juga bisa menceritakan permasalahan yang dihadapi di media sosial pada orang tua dan teman sebayanya untuk mendapatkan rasa aman dan solusi (d'Haenens et al, 2013).

Penelitian ini menemukan bahwa hubungan persahabatan sangat berpengaruh positif terhadap online resilience. Hal ini sejalan dengan van Harmelen et al. (2017), pertemanan remaja dan dukungan keluarga berpengaruh positif signifikan terhadap resiliensi remaja dan pertemanan remaja menjadi prediktor terkuat dibandingkan dukungan keluarga remaja. Menurut penelitian Graber et al. (2016) dan Australian Institute of Family Studies (2019), remaja yang memiliki setidaknya satu orang yang dapat berperan sebagai teman baik dapat membangun resiliensi bagi remaja. Teman sebaya yang baik berperan sebagai sosok yang dipercayai remaja dalam berkeluh kesah dan mengatasi masalah di media sosial. Dengan pemahaman yang sama terkait penggunaan media sosial, remaja dapat menerima saran yang lebih efektif terkait permasalahan di media sosial (Bradbury et al., 2018) Sebaliknya, remaja yang tidak memiliki teman baik sangat rentan dengan stres akibat pengalaman negatif di internet. Kesepian akibat ketiadaan teman berperan terhadap adiksi internet (Musetti, Corsano, Boursier, \& Schimmenti, 2020) dan adiksi internet meningkatkan pengaruh negatif media sosial melalui paparan risiko online (Wisniewski et al., 2015).

Hubungan persahabatan dan regulasi emosi dapat dibangun oleh lingkungan terdekat remaja, yaitu sekolah. Waktu bersama menjadi salah satu kunci penting dalam membangun hubungan persahabatan. Seorang individu perlu menghabiskan setidaknya 94 jam bersama untuk mengubah posisi "kenalan" (acquaintances) individu lain menjadi "teman biasa" (casual friends), 164 jam bersama untuk mengubah posisi "teman biasa" menjadi "teman" (friends), dan 219 jam bersama untuk mengubah teman menjadi teman baik/sahabat (good/best friends) (Hall, 2019). Untuk membina hubungan, remaja tidak cukup bersama dalam satu ruang saja. Remaja memerlukan variasi aktivitas untuk melatih kemampuan membina hubungan persahabatan dan regulasi emosi. Sekolah dapat mendorong atau mengoptimalkan kegiatan yang melibatkan siswa remaja bekerja secara kelompok (tugas sekolah, ekstrakulikuler, lainnya) sehingga memperbesar kesempatan remaja untuk mengembangkan hubungan persahabatan dan melatih regulasi emosi dengan lebih baik. Hal ini didukung oleh temuan bahwa tugas kelompok terbukti dapat meningkatkan hubungan teman sebaya dan mengurangi masalah emosional (van Ryzin \& Roseth, 2018).

\section{SIMPULAN DAN SARAN}

Hasil uji regresi penelitian ini membuktikan beberapa variabel yang berkontribusi dalam online resilience remaja. Jenis kelamin berpengaruh negatif terhadap online resilience yang artinya dalam penelitian ini perempuan memiliki online resilience yang lebih rendah dari laki-laki. Pendapatan per kapita berpengaruh terhadap online resilience, artinya remaja yang berasal dari keluarga dengan pendapatan per kapita yang baik memiliki online resilience yang lebih baik juga. Penelitian ini tidak menemukan adanya pengaruh kelekatan remaja-orang tua terhadap online resilience. Regulasi emosi penilaian ulang dan hubungan persahabatan remaja berpengaruh signifikan positif terhadap online resilience. Berdasarkan hasil yang 
diperoleh dari penelitian ini maka saran pertama yang dapat diberikan untuk pemerintah maupun lembaga yang berkaitan dengan keluarga dan anak adalah perlunya perhatian lebih pada remaja perempuan mengingat remaja perempuan memiliki online resilience yang lebih rendah dibandingkan remaja lakilaki. Kedua, peningkatan online resilience remaja dapat dilakukan dengan meningkatkan hubungan persahabatan dan regulasi emosi penilaian ulang. Lingkungan terdekat remaja dapat memprogram aktivitas yang membuka peluang remaja untuk memperdalam persahabatan dan melatih regulasi emosi.

Keterbatasan penelitian ini adalah penarikan contoh dengan metode non probability sampling sehingga hasil penelitian ini tidak dapat berlaku umum terhadap populasi. Pengukuran online resilience juga diukur secara umum pada remaja tanpa mengukur pengalaman negatif yang dialami remaja sehingga implikasi pengaruh online resilience tidak spesifik untuk remaja yang mengalami pengalaman negatif di media sosial. Penelitian selanjutnya disarankan dapat melakukan penarikan contoh dengan metode random sampling pada populasi korban pengalaman negatif di internet serta mengukur atau membandingkan variabel penelitian berdasarkan tingkat pengalaman negatif remaja di media sosial.

\section{DAFTAR PUSTAKA}

[APJII] Asosiasi Penyelenggara Jasa Internet Indonesia. (2018). Penetrasi dan Profil Perilaku Pengguna Internet Indonesia 2018. Jakarta, ID: Asosiasi Penyelenggara Jasa Internet Indonesia. Retrieved from https://apjii.or.id/content/read/39/410/HasilSurvei-Penetrasi-dan-Perilaku-PenggunaInternet-Indonesia-2018

[APJII] Asosiasi Penyelenggara Jasa Internet Indonesia. (2020). Laporan Survei Internet APJII 2019-2020 (Q2). Jakarta, ID: Asosiasi Penyelenggara Jasa Internet Indonesia. Retrieved from https://apjii.or.id/survei

Armsden, G. C., \& Greenberg, M. T. (1987). The inventory of parent and peer attachment: Individual differences and their relationship to psychological well-being in adolescence. Journal of Youth and Adolescence, 16(5), 427-453. doi: 10.1007/BF02202939

Australian Institute of Family Studies. (2019). Adolescents' resilience. Retrieved from https://aifs.gov.au/publications/adolescents -resilience

Bender, A., \& Ingram, R. (2018). Connecting attachment style to resilience: Contributions of self-care and selfefficacy. Personality and Individual Differences, $130, \quad 18-20 . \quad$ doi: 10.1016/J.PAID.2018.03.038

Bradbury, S. L., Dubow, E. F., \& Domoff, S. E. (2018). How do adolescents learn cybervictimization coping skills? An examination of parent and peer coping socialization. Journal of Youth and Adolescence, 47(9), 1866-1879. doi: 10.1007/s10964-0180812-y

Connor, K. M., \& Davidson, J. R. (2003). Development of a new resilience scale: The Connor-Davidson Resilience Scale (CD-RISC). Depression and Anxiety, 18(2), 76-82. doi: 10.1002/da.10113

D'Haenens, L., vandoninck, S., \& Donoso, V. (2013). How to cope and build online resilience?. Retrieved from http://eprints.Ise.ac.uk/48115/1/How\%20to \%20cope\%20and\%20build\%20online\%20r esilience\%20(Isero).pdf

Erdem, Ş. (2017). Attachment to parents and resilience among high school students. Journal of Positive Psychology and Wellbeing, 1(1), 22-33. Retrieved from http://www.journalppw.com/index.php/JPP W/article/view/3

Firdaus, I. K., \& Kelly, E. K. (2019). Pengaruh pola asuh terhadap online resilience. Jurnal Psikologi: Jurnal Ilmiah Fakultas Psikologi Universitas Yudharta Pasuruan, 6(1), 20-38. Retrieved from https://jurnal.yudharta.ac.id/v2/index.php/lL MU-PSIKOLOGI/article/view/1696

Gayatri, G., Rusadi, U., Meiningsih, S. Mahmudah, D., Sari, D., Kautsarina, Karman, \& Nugroho, A.C. (2015). Digital citizenship safety among children and adolescents in Indonesia. Jurnal Penelitian dan Pengembangan Komunikasi dan Informatika, 6(1), 1-16. Retrieved from https://jurnal.kominfo.go.id/index.php/jppki/ article/view/579

Goleman, D. (2018). Kecerdasan emosional. (T. Hermaya, Trans.). Jakarta, ID: PT Gramedia Pustaka Utama. (Original work published 1995)

Graber, R., Turner, R., \& Madill, A. (2016). Best friends and better coping: Facilitating psychological resilience through boys' and girls' closest friendships. British Journal of 
Psychology, 107(2), 338-358. doi: 10.1111/bjop.12135

Gross, J. J. (1999). Emotion regulation: Past, present, future. Cognition and Emotion, 13(5), $10.1080 / 026999399379186$

Gross, J. J. (2001). Emotion regulation in adulthood: Timing is everything. Current Directions in Psychological Science, 10(6), 214-219. doi: 10.1111/1467-8721.00152

Gross, J.J., \& John, O.P. (2003). Individual differences in two emotion regulation processes: Implications for affect, relationships, and well-being. Journal of Personality and Social Psychology, 85, 348-362. doi: 10.1037/00223514.85.2.348

Hall, J. A. (2019). How many hours does it take to make a friend?. Journal of Social and Personal Relationships, 36(4), 1278-1296. doi: $10.1177 / 0265407518761225$

He, J., Chen, X., Fan, X., Cai, Z., \& Hao, S. (2018). Profiles of parent and peer attachments of adolescents and associations with psychological outcomes. Children and Youth Services Review, 94, 163-172. doi: 10.1016/j.childyouth.2018.10.001

Hendriani, W. (2017). Menumbuhkan online resilience pada anak di era teknologi digital. In Prosiding Temu IImiah Nasional $X$ Ikatan Psikologi Perkembangan Indonesia, $1 . \quad$ Retrieved from http://jurnal.unissula.ac.id/index.php/ippi/ar ticle/download/2173/1636

Hendriani, W. (2018). Resiliensi psikologis: Sebuah pengantar. Jakarta, ID: Prenadamedia Group.

Hinduja, S., \& Patchin, J. W. (2017). Cultivating youth resilience to prevent bullying and cyberbullying victimization. Child Abuse \& Neglect, 73, 51-62. doi: 10.1016/j.chiabu.2017.09.010

Hou, X. L., Wang, H. Z., Guo, C., Gaskin, J., Rost, D. H., \& Wang, J. L. (2017). Psychological resilience can help combat the effect of stress on problematic social networking site usage. Personality and Individual Differences, 109, 61-66. doi: 10.1016/j.paid.2016.12.048

Karreman, A., \& Vingerhoets, A. J. (2012). Attachment and well-being: The mediating role of emotion regulation and resilience. Personality and Individual differences, 53(7), 821-826. doi: 10.1016/j.paid.2012.06.014

Maesaroh, S., Sunarti, E., \& Muflikhati, I. (2019). Ancaman, faktor protektif, dan resiliensi remaja di Kota Bogor. Jurnal IImu Keluarga \& Konsumen, 12(1), 63-74. doi: 10.24156/jikk.2019.12.1.63

Megawangi, R. (2015). Kelekatan ibu-anak: Kunci membangun bangsa. Depok, ID: Indonesia Heritage Foundation.

Mendelson, M. J., \& Aboud, F. E. (1999). Measuring friendship quality in late adolescents and young adults: McGill Friendship Questionnaires. Canadian Journal of Behavioural Science/Revue Canadienne Des Sciences Du Comportement, 31(2), 130-132. doi:10.1037/h0087080

Mestre, J. M., Núñez-Lozano, J. M., GómezMolinero, R., Zayas, A., \& Guil, R. (2017). Emotion regulation ability and resilience in a sample of adolescents from a suburban area. Frontiers in Psychology, 8, 1980. doi: 10.3389/fpsyg.2017.01980

Musetti, A., Corsano, P., Boursier, V., \& Schimmenti, A. (2020). Problematic internet use in lonely adolescents: The mediating role of detachment from parents. Clinical Neuropsychiatry, 17(1), 3-10. doi: 10.36131/clinicalnpsych20200101

Nesi, J., \& Prinstein, M. J. (2015). Using social media for social comparison and feedbackseeking: Gender and popularity moderate associations with depressive symptoms. Journal of Abnormal Child Psychology, 43(8), 1427-1438. doi: 10.1007/s10802-015-0020-0

Parno. (2019). 16,4 juta pengguna medsos asal Jawa Barat. Website Resmi Pemerintah Daerah Provinsi Jawa Barat. Retrieved from https://jabarprov.go.id/index.php/news/327 77/2019/04/24/164-juta-PenggunaMedsos-Asal-Jawa-Barat

Perchtold, C. M., Papousek, I., Fink, A., Weber, H., Rominger, C., \& Weiss, E. M. (2019). Gender differences in generating cognitive reappraisals for threatening situations: Reappraisal capacity shields against depressive symptoms in men, but not women. Frontiers in psychology, 10, 553. doi: 10.3389/fpsyg.2019.00553

Schwarz, B., Stutz, M., \& Ledermann, T. (2012). Perceived interparental conflict and early adolescents' friendships: The role of attachment security and emotion regulation. 
Journal of Youth and Adolescence, 41(9), 1240-1252. doi: 10.1007/s10964-0129769-4

Sukmaningpraja, A., \& Santhoso, F. H. (2017). Peran regulasi emosi terhadap resiliensi pada siswa sekolah berasrama berbasis semi militer. Gadjah Mada Journal of Psychology (GamaJoP), 2(3), 184-191. doi: 10.22146/gamajop.36944

Susilo, B. (2018). Pemasaran Digital: Segmentasi Demografi Pengguna Media Sosial di Kota Pontianak. Jurnal Eksplora Informatika, 8(1), 69-79. doi: 10.30864/eksplora.v8i1.163

Triastuti, E., Prabowo, D. A. I., \& Nurul, A. (2017). Kajian Dampak Penggunaan Media Sosial Bagi Anak dan Remaja. Depok, ID: Pusat Kajian Komunikasi FISIP UI. Retrieved from http://repository.unugha.ac.id/16/1/seribuku literasidigital-

kajiandampakmediasosialbagianakdanrem aja-puskakomui-180201035158.pdf

van Harmelen, A.-L. V., Kievit, R. A., Ioannidis, K., Neufeld, S., Jones, P. B., Bullmore, E., ... Goodyer, I. (2017). Adolescent friendships predict later resilient functioning across psychosocial domains in a healthy community cohort. Psychological Medicine, 47(13),
2312-2322.

doi: $10.1017 / \mathrm{s} 0033291717000836$

van Ryzin, M. J., \& Roseth, C. J. (2018). Cooperative learning in middle school: A means to improve peer relations and reduce victimization, bullying, and related outcomes. Journal of Educational Psychology, 110(8), 1192. doi: $10.1037 /$ edu0000265

Vissenberg, J., \& d'Haenens, L. (2020). Online Risks, Harm, and Resilience: Flemish Findings from the 2020 EU Kids Online Survey. Leuven, BE: EU Kids Online. Retrieved from https://lirias.kuleuven.be/retrieve/566856

Widuri, E. L. (2012). Regulasi emosi dan resiliensi pada mahasiswa tahun pertama. Humanitas: Jurnal Psikologi Indonesia, 9(2), 147-156. doi: 10.26555/humanitas.v9i2.341

Wisniewski, P., Jia, H., Wang, N., Zheng, S., Xu, H., Rosson, M. B., \& Carroll, J. M. (2015, April). Resilience mitigates the negative effects of adolescent internet addiction and online risk exposure. In Proceedings of the 33rd Annual ACM Conference on Human Factors in Computing Systems (pp. 4029-4038). ACM. doi: 10.1145/2702123.2702240 